\title{
The dome technique: a new surgical technique to enhance soft-tissue margins and emergence profiles around implants placed in the esthetic
}

\section{zone}

This article was published in the following Dove Press journal:

Clinical, Cosmetic and Investigational Dentistry

\author{
Tassos Irinakis' \\ Salwa Aldahlawi ${ }^{1,2}$ \\ 'Faculty of Dentistry, University of \\ British Columbia, Vancouver, BC, \\ Canada; ${ }^{2}$ Faculty of Dentistry, Umm \\ Al-Qura University, Mecca, Saudi \\ Arabia
}

\begin{abstract}
Achieving symmetry of the soft-tissue margins between anterior maxillary dentalimplant restorations and adjacent teeth is a therapeutic challenge for both the implant surgeon and the restorative dentist. This article describes a modified procedure utilizing autogenous connective-tissue grafts to improve primarily buccal soft-tissue margins and secondarily interproximal tissues around tooth-bound single dental implants. This technique has the advantage of allowing for coronal augmentation of the peri-implant soft tissue while maximizing the blood supply to the area by using tunneling-technique principles. A detailed description of the technique and a case with a stable result over 24 months after crown placement is presented.

Keywords: esthetic dental treatment, peri-implant soft tissue, autogenous connective-tissue grafts, dental implants, soft tissue augmentation, tunnel technique
\end{abstract}

\section{Introduction}

Following tooth loss, a considerable reduction in hard- and soft-tissue volume can be expected. ${ }^{1,2}$ In the anterior maxilla, tissue loss can make future implant restorations more challenging and less predictable in terms of achieving and maintaining favorable soft-tissue-emergence profiles. This is even more evident in esthetically demanding situations, like patients with a high smile line. ${ }^{3}$ Many factors influence the final esthetics of a case, including the three-dimensional position of the implant, ${ }^{4}$ the implant-fixture angulation, ${ }^{5}$ the position of the facial bone crest and the distance from the contact point to the crest of the bone and contact point to implant platform, ${ }^{6}$ and the quantity and quality of the soft-tissue envelope. ${ }^{7}$ Even with careful implant planning and placement, marginal gingival recession of $0.5-1 \mathrm{~mm}$ has been a common finding with single-tooth implants. ${ }^{8,9}$ This is partly attributed to bone remodeling after implant surgery, ${ }^{10}$ and occurs regardless of implant-placement protocol used. ${ }^{11}$ Patients with thin gingival biotype are more frequently affected by peri-implant soft-tissue recession, which tends to progress with time. ${ }^{6,8,12}$ Although overall patient satisfaction with anterior dental implants is high, ${ }^{9,13,14}$ having disharmony between gingival margins and adjacent teeth decreases the patient-satisfaction rate considerably. ${ }^{9}$

Advances in materials and refined surgical techniques of soft-tissue manipulation have led to optimized soft-tissue volume before and - to a lesser extent - after implant placement. Many techniques in the literature have focused on papillary reconstruction, with very few addressing buccal soft-tissue margins. ${ }^{15-17}$ The use of connective-tissue
Correspondence: Salwa Aldahlawi Faculty of Dentistry, University of British Columbia 2199 Wesbrook Mall, Vancouver, BC V6T IZ3, Canada

Tel +966500559365

Fax +l 6046085647

Email sadahlaawi@uqu.edu.sa 
grafts (CTGs) has improved the esthetic outcome of dental implants, mainly due to enhancing alveolar bone contours. ${ }^{13}$ In most of the literature, the recipient site is prepared by raising a buccal flap, and the CTG is then inserted underneath the buccal flap and secured with sutures. However, raising a flap can disturb the blood supply to the periosteum, and subsequently results in bone resorption. ${ }^{18}$ In addition, having the flap prepared in the area negatively affects the interdental tissue and compromises future papilla height. ${ }^{15}$

The aim of this article is to present a surgical technique to improve primarily buccal soft-tissue margins and secondarily interproximal tissues around single dental implants so that the peri-implant tissues mimic those of the adjacent natural teeth utilizing tunneling-technique principles.

\section{The dome technique}

TI created this technique for cases where a tooth-bound single implant or two adjacent implants are placed in the esthetic zone, especially when it becomes apparent that the future crown facial margins and the soft-tissue zenith will be unfavorably more apical to the contralateral tooth and to the ideal and desired position. The name of the technique addresses the placement of the CT, as it is layered over the implant and takes the shape of an inverted dome.

A prerequisite of the technique is to have adequate resilient soft tissue around the implant. This is achieved by using a healing abutment at the time of implant placement to shape the peri-implant tissues and create a space for the future dome CTG (Figure 1A and B). After the successful integration of the implant, but not less than 6 weeks, the healing abutment is removed and replaced by a flat cover screw or closure cap (Figure 1C and D). A primary circumferential incision is performed at the level of the implant head using a microsurgical blade or a $15 \mathrm{C}$ blade to produce a partialthickness circumferential flap or "dome" over the implant.

The partial-thickness dissection is carried all around the implant on the buccal, palatal, and interdental areas with a thin and curved periosteal elevator, which is used as a tunneling instrument (Figure 1E). Careful use of an Orban knife as an alternative is possible, but perforation of the buccal flap (which is frequently thin and fragile) must be avoided. Via the usual steps of a tunneling technique, the interproximal papillae are detached from the roots and "lifted" to allow the harvested CTG to spread under the papillae, as well as buccally and palatally (Figure 1F). It is imperative to refrain from root planing the interproximal root surfaces to avoid removal of the fiber attachments and risking additional postoperative recession.
The second step in the technique involves the harvesting of an autogenous subepithelial CTG from the contralateral side of the palate (Figure 1G). A long, wide graft is needed to fully cover the implant site and be placed under the papillae (Figure $1 \mathrm{H})$. The donor site is sutured with 4-0 Vicryl continuous sutures with or without the application of cyanoacrylate tissue adhesive.

The final step in the procedure is to position and secure the newly acquired autogenous tissue in the created dome pouch. The CTG is inserted carefully in the buccopalatal direction covering the implant (Figure 1I). The graft is stabilized first along the buccal aspect by a blind suture that penetrates the overlying buccal tissue and the underlying CTG using 6-0 or 5-0 chromic gut or nylon sutures (Figure $1 \mathrm{~J}$ ).

The rest of the CT is inserted into the palatal aspect and then spread laterally underneath the interdental papilla, thus creating a dome-shaped tissue. Further suturing takes place to secure the graft in place, which includes a crossover suture (Figure $1 \mathrm{~K}$ and L). Having more than two-thirds of the graft covered underneath the flap is critical to ensure survival of the part covering the implant head, which remains exposed. The graft is allowed to heal for 6-8 weeks. It is important to adjust the temporary prosthesis during this time to avoid any pressure on the graft during healing.

\section{Uncovering the implant}

A semilunar incision is created over the palatal half of the estimated implant head (Figure 2A). A tissue-biopsy punch is used to demarcate the shape of the incision by applying light pressure against the overlying tissue (Figure 2B). A 15C surgical blade is used to follow the palatal half of the demarcation and to remove only the palatal tissue, thus preserving the new augmented buccal tissue (Figure 2C). Small lateral incisions at the line angles will allow the surgeon to stretch the newly formed buccal tissue. This will allow slight movement of the tissue, and permits the seating of the new healing abutment. The new healing abutment is usually taller than the original one used, as a new tissue has formed. Suturing is not usually required at this phase (Figure 2D).

\section{Case report}

Written informed consent was provided by the patient to have the case details and images published. A 67-year-old female presented with a chief complaint of a fractured upper left central incisor. She presented with a high smile line, and esthetics were extremely important to her. The tooth was fractured at the gingival margin and deemed unrestorable (Figure 3A and B). An immediate implant (Nobel Active 

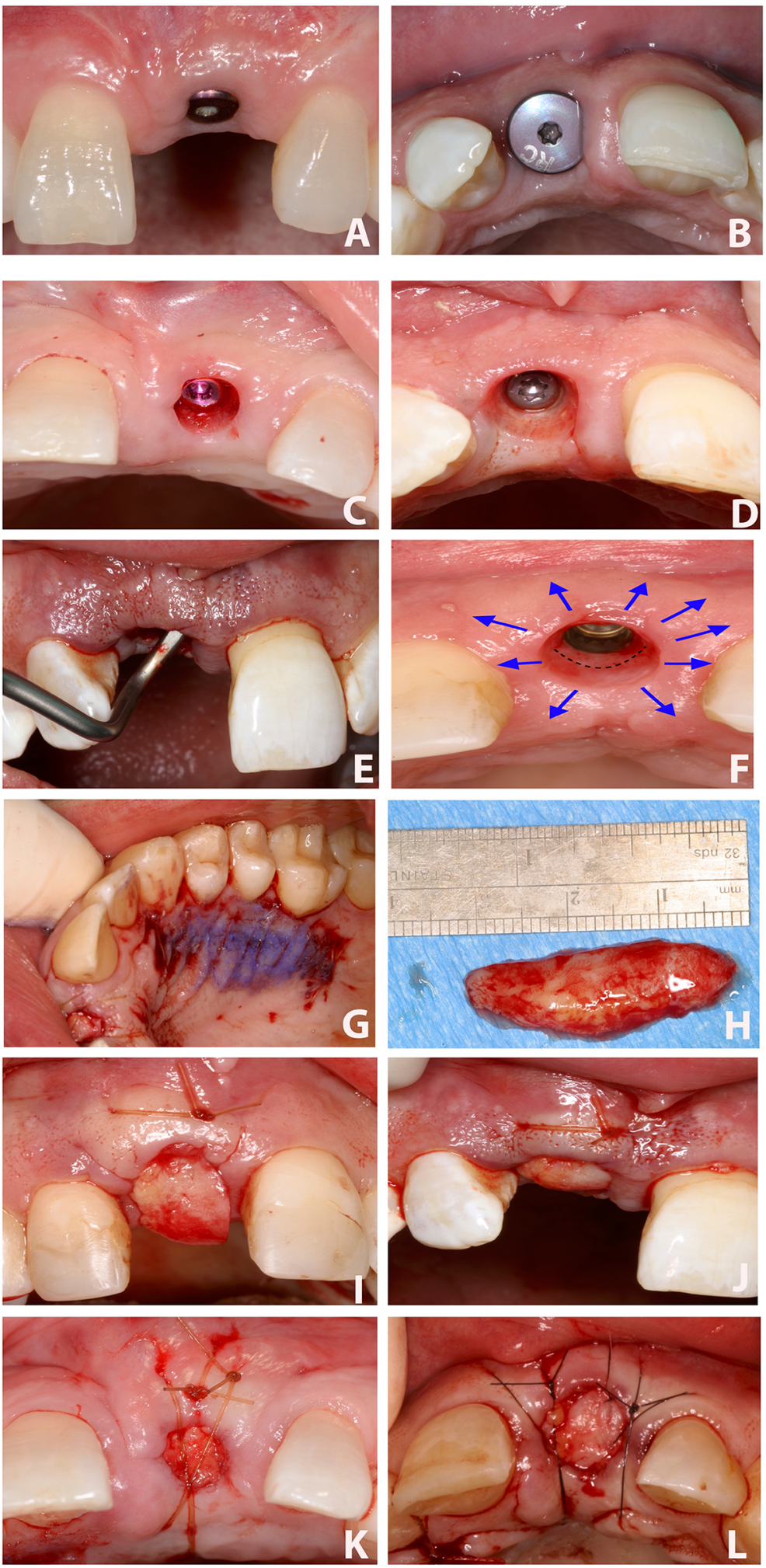

Figure I Surgical steps of Dome technique.

Notes: (A, B) Having a healing abutment for 6-8 weeks is a prerequisite for the dome technique. The healing abutment helps to shape the peri-implant tissue. (C, D) When the healing abutment is removed, a space is created for the dome connective-tissue graft. (E) Partial-thickness blunt dissection is carried out all around the implant on the buccal, palatal, and interdental areas with a bent periosteal elevator that is used as a tunneling instrument. $(\mathbf{F})$ The dotted line represents the circumferential incision line, and the arrows show the extent/spread of the tunnel preparation in all directions. (G, H) A connective-tissue graft is harvested from the contralateral side of the palate to allow for harvesting of the largest possible graft. (I, J) The CTG is carried to the "dome" pouch over the implant and inserted carefully in the buccal-palatal direction. It is then stabilized first along the buccal aspect by "blind" suture that penetrates the overlying buccal tissue and the underlying CTG. (K, L) The rest of the connective tissue is passed over the implant head and inserted into the palatal aspect and then "spread" laterally underneath the interdental papilla and sutured in place.

Abbreviation: CTG, connective-tissue graft. 

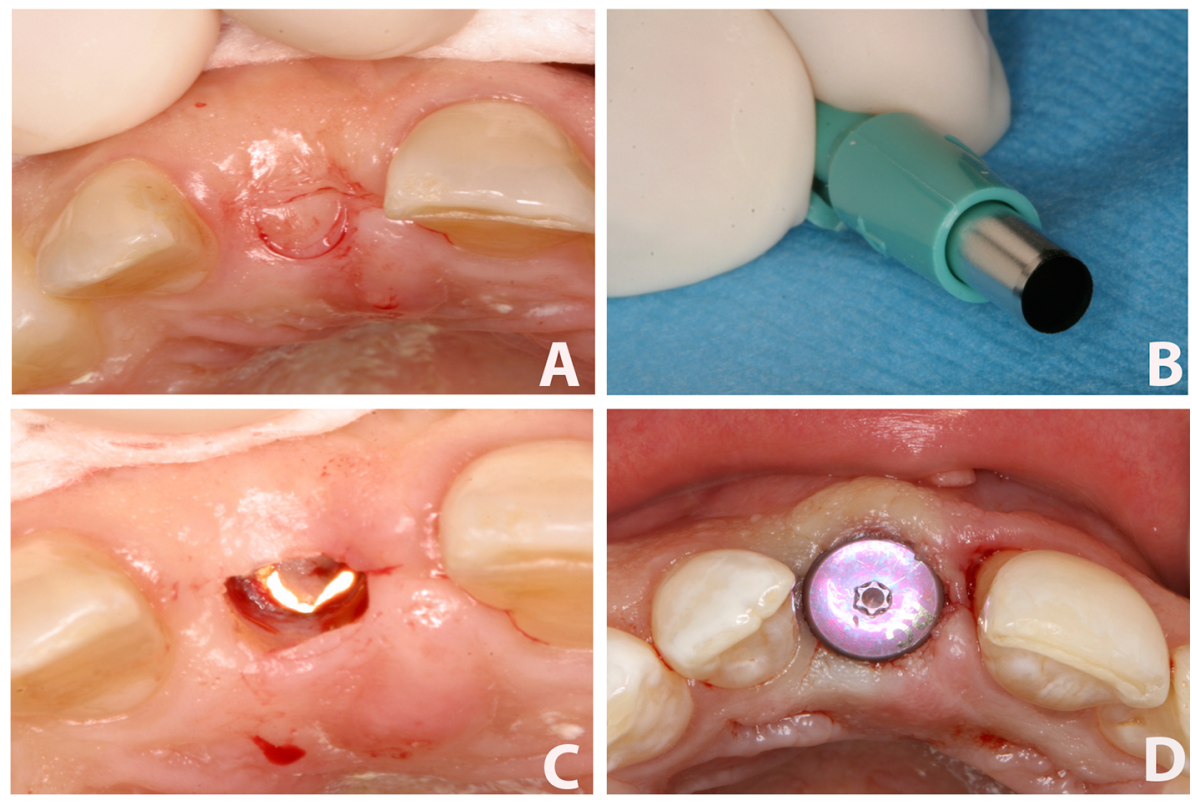

Figure 2 Uncovering the implant after healing of the dome connective tissue.

Notes: (A) A semilunar incision is created over the estimated implant site. (B) A punch-biopsy instrument is used to demarcate the initial incision. (C) Only the palatal half of the tissue is removed. This will allow access to the implant and the cover screw, which must be replaced by a healing abutment. (D) A healing abutment of sufficient length and width is chosen to support the newly formed tissue.

RP 4.3×13 mm; Nobel Biocare, Gothenburg, Sweden) was placed at the time of extraction in an ideal three-dimensional position. Excellent primary stability at a torque of $40 \mathrm{Ncm}$ was achieved. A Nobel RP healing abutment $5 \times 5 \mathrm{~mm}$ was also placed during the healing period. After 5 months of healing, an osseointegration check was performed with a magnetic resonance-frequency device (Osstell Mentor), and the implant scored favorably, with an implant-stability quotient of 79. At this stage, it was clear that the future crown margin would be apical to that of the contralateral tooth, thus creating a gingival margin disharmony (Figure $3 \mathrm{C}-\mathrm{E}$ ). As per the dome-technique protocol, we replaced the healing abutment with a cover screw.

The recipient bed was prepared by a partial-thickness incision and blunt dissection utilizing a curved, thin periosteal elevator (Figure 3F), which extended along the facial aspect of the implant and laterally under the adjacent mesial and distal interdental papillae. CT was harvested from the palate (Figure 3G), inserted under the buccal flap first, and then laid over the implant head, extending into the palatal and interdental areas of the prepared surgical bed. 5-0 chromic gut sutures were used to stabilize the graft (Figure 3H and I). The patient was instructed on the use of $0.12 \%$ chlorhexidine mouthwash, and was seen periodically for professional oralhygiene maintenance during the follow-up period. Healing was uneventful (Figure 3J). After 6 weeks, the implant was exposed and a new healing abutment placed (Figure $3 \mathrm{~K}$ ). The patient was referred for the restorative phase of the treatment and received a cement-retained crown. The final results were esthetically satisfying, with harmonized gingival margins on both central incisors. The tissue surrounding the implant was thick and healthy (Figure 3L and $\mathrm{M}$ ). The patient was observed up to 24 months following crown insertion, with stable results and maintenance of the marginal gingival tissue (Figure 4).

\section{Discussion}

The advantage of the dome CT technique is that it allows for both buccal and coronal augmentation of local soft tissue, while maximizing blood supply to the area by using tunneling-technique principles. It enhances and augments the peri-implant tissue foundation for a favorable facial and interproximal restorative emergence profile. As this technique does not involve raising an independent buccal flap, the gingival tissue of the adjacent teeth is not compromised, and thus the risk of recession and formation of black triangles on the adjacent teeth is minimized. Gonzalez et al reported the use of CTG at immediate implant placement to avoid soft-tissue-margin disharmony between the future crown and adjacent teeth. ${ }^{17}$ In the dome technique, soft-tissue augmentation is delayed until successful integration of the implant is achieved. In the authors' experience, shaping the peri-implant soft tissue by the use of healing abutment during the initial healing phase has the advantage of providing 

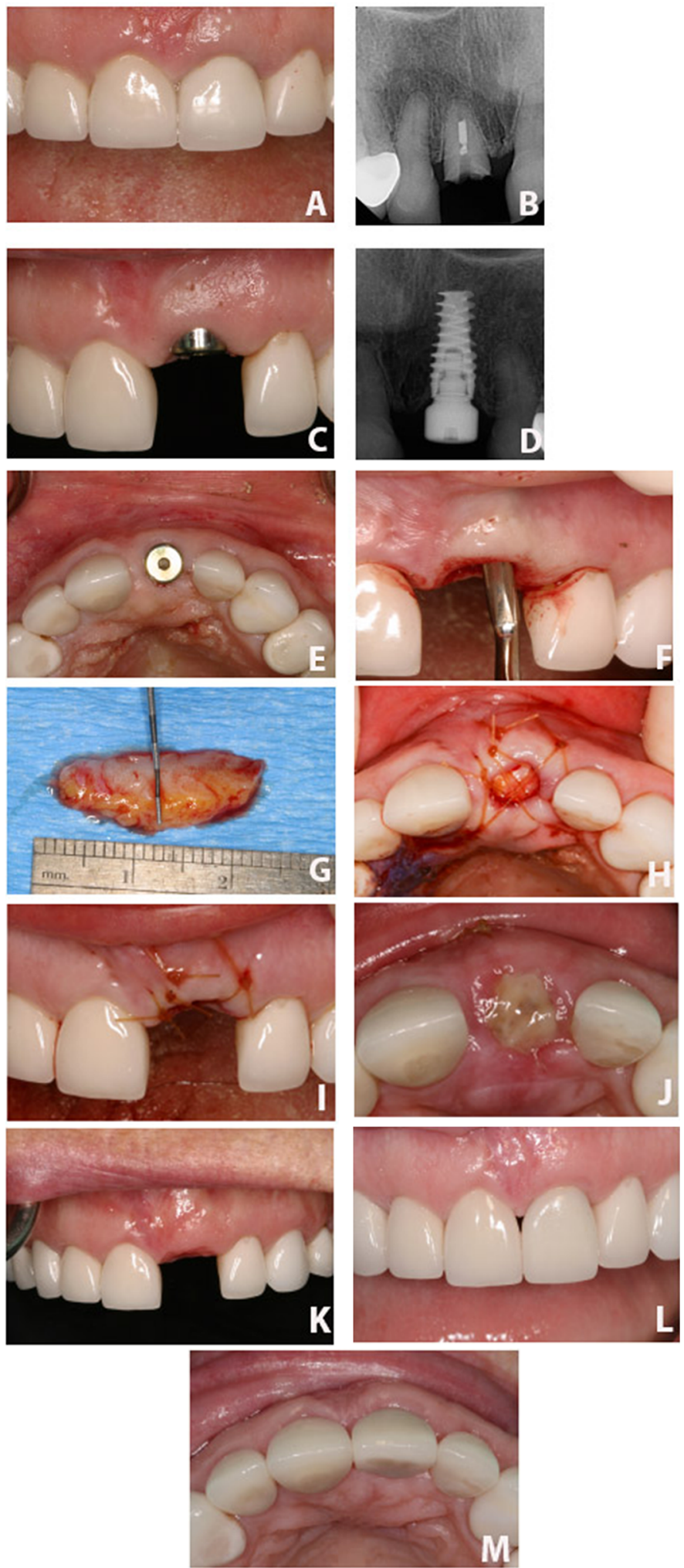

Figure 3 Case report.

Notes: (A) Initial presentation. Tooth 21 was fractured subgingivally, and tissue was inflamed and cyanotic. (B) Periapical radiography showing the remaining short root and level of interproximal bone. (C) Presentation at osseointegration check. Peri-implant tissue is healthy, but located at an apical level when compared to the adjacent tooth. (D) Periapical radiography of the implant replacing tooth 2 I. (E) Occlusal view of the healing abutment. (F) Tunnel preparation extending apically using curved elevator. (G) Connective-tissue graft harvested from the contralateral side of the palate. Wide, thick tissue is needed. (H, I) The CTG is inserted into the dome first buccally then palatally and stabilized by 6-0 sutures. At least two-thirds of the graft has to be covered to allow the survival of the uncovered part. (J) Healing of the area at 2 weeks. (K) Amount of vertical tissue augmentation achieved at the uncovering of the implant at 6 weeks. (L) Final cement-retained crown. Adequate esthetic results were achieved with harmonious gingival margin between the implant and the adjacent teeth. $(\mathbf{M})$ Occlusal view showing amount of augmented tissue on the buccal aspect.

Abbreviation: CTG, connective-tissue graft. 

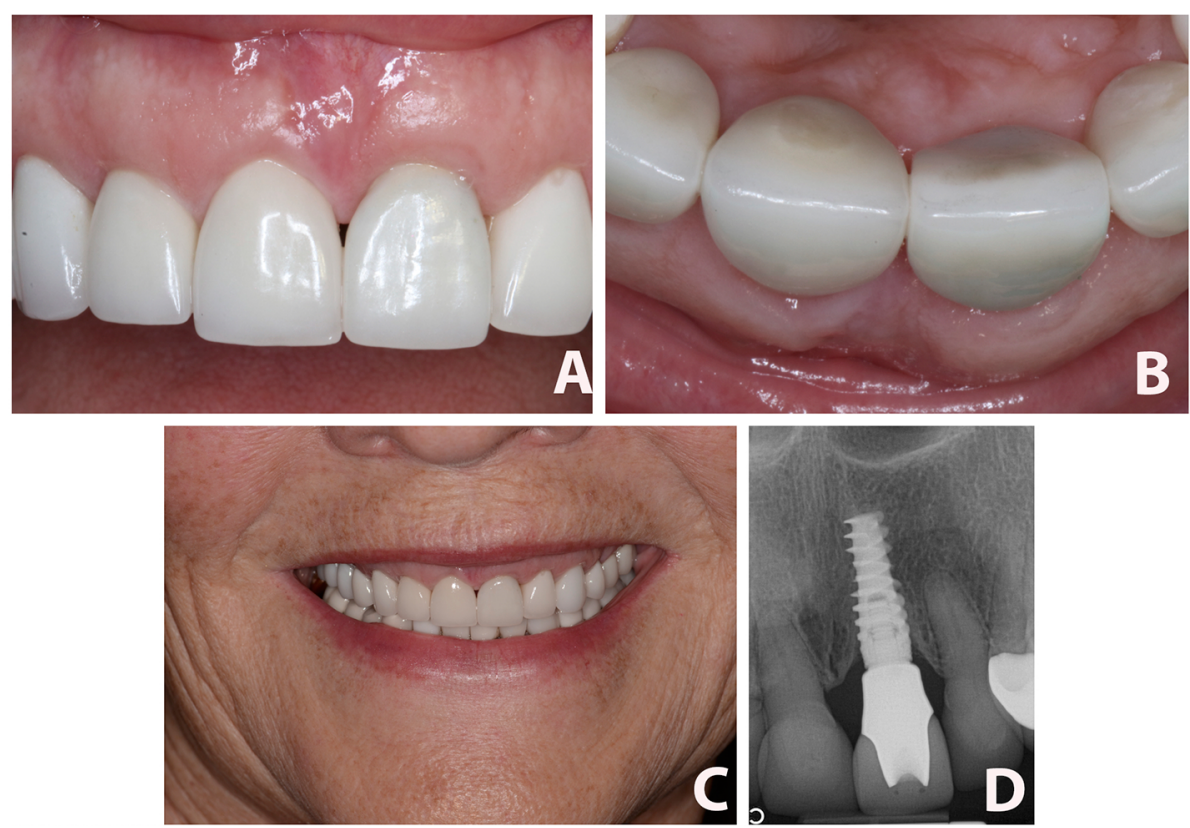

Figure 4 24-Month follow-up.

Notes: (A) Stable esthetic results were achieved with the gingival margins on both central incisors at equal levels. (B) Buccal soft-tissue augmentation is maintained. (C) Patient smile. (D) Periapical radiography of the implant replacing tooth 21 with stable bone level.

a resilient soft tissue, with less potential for recession after surgical manipulation, thus increasing the predictability of coronal tissue gain.

This technique is still an additional surgical procedure that requires exposure of the implant, and additional time is needed for healing, which adds to the length of the treatment. It has certain risks, and should be performed by an experienced clinician, as perforation of the tissue during tunneling preparation can occur.

Although the use of CT has demonstrated a predictable increase of soft-tissue volume in most studies, ${ }^{19}$ it has also been demonstrated that some shrinkage might occur over time and is subject to individual variation..$^{20}$ The long-term stability of soft tissue around an implant restoration depends largely on the presence of adequate soft-tissue volume in a vertical and buccolingual direction. ${ }^{21}$ To date, there is no consensus on the soft-tissue volume required to have a stable peri-implant gingival support. ${ }^{22}$ In general, most studies have demonstrated that $2 \mathrm{~mm}$ of buccal soft tissue is critical for an esthetic outcome. ${ }^{7}$ However, none of the studies identified the critical soft-tissue volume in a three-dimensional way. ${ }^{23,24}$ The present case report confirms the dome technique has the potential of augmenting the buccal soft-tissue margin around a single implant in the esthetic zone, and documents a stable esthetic result for over 24 months after restoration of the dental implant. However, the technique requires longer-term data to document the maintenance of esthetic results and volumetric stability.

\section{Conclusion}

Soft-tissue augmentation is frequently needed to achieve a gingival margin on single-site implants that is harmonious with the adjacent teeth. The dome technique described in this article provides the advantage of soft-tissue augmentation around single implants, with minimal disturbance to the adjacent dentition. The authors' clinical experience with this technique for the last several years has shown stable and esthetically favorable clinical results in term of vertical and horizontal soft-tissue augmentation.

\section{Author contributions}

TI designed the treatment concept and undertook all surgical procedures, and SA wrote the manuscript and reviewed the available literature. Both authors contributed toward data analysis, drafting and revising the paper and agree to be accountable for all aspects of the work. Both authors read and approved the final manuscript.

\section{Disclosure}

The authors report no conflicts of interest in this work.

\section{References}

1. Tan WL, Wong TL, Wong MC, Lang NP. A systematic review of post-extractional alveolar hard and soft tissue dimensional changes in humans. Clin Oral Implants Res. 2012;23(Suppl 5):1-21.

2. Araujo MG, Silva CO, Misawa M, Sukekava F. Alveolar socket healing: what can we learn? Periodontol 2000. 2015;68(1):122-134. 
3. Chappuis V, Araujo MG, Buser D. Clinical relevance of dimensional bone and soft tissue alterations post-extraction in esthetic sites. Periodontol 2000. 2017;73(1):73-83.

4. Buser D, Chappuis V, Belser UC, Chen S. Implant placement post extraction in esthetic single tooth sites: when immediate, when early, when late? Periodontol 2000. 2017;73(1):84-102.

5. Le BT, Borzabadi-Farahani A, Pluemsakunthai W. Is buccolingual angulation of maxillary anterior implants associated with the crestal labial soft tissue thickness? Int J Oral Maxillofac Surg. 2014;43(7): 874-878.

6. Kan JY, Rungcharassaeng K, Umezu K, Kois JC. Dimensions of periimplant mucosa: an evaluation of maxillary anterior single implants in humans. J Periodontol. 2003;74(4):557-562.

7. Linkevicius T, Puisys A, Steigmann M, Vindasiute E, Linkeviciene L. Influence of vertical soft tissue thickness on crestal bone changes around implants with platform switching: a comparative clinical study. Clin Implant Dent Relat Res. 2015;17(6):1228-1236.

8. Nisapakultorn K, Suphanantachat S, Silkosessak O, Rattanamongkolgul S. Factors affecting soft tissue level around anterior maxillary single-tooth implants. Clin Oral Implants Res. 2010;21(6): $662-670$.

9. Suphanantachat S, Thovanich K, Nisapakultorn K. The influence of peri-implant mucosal level on the satisfaction with anterior maxillary implants. Clin Oral Implants Res. 2012;23(9):1075-1081.

10. Linkevicius T, Apse P. Biologic width around implants: an evidencebased review. Stomatologija. 2008;10(1):27-35.

11. Hof M, Pommer B, Ambros H, Jesch P, Vogl S, Zechner W. Does timing of implant placement affect implant therapy outcome in the esthetic zone? A clinical, radiological, esthetic, and patient-based evaluation Clin Implant Dent Relat Res. 2015;17(6):1188-1199.

12. Zhao X, Qiao SC, Shi JY, Uemura N, Arai K, Lai HC. Evaluation of the clinical and esthetic outcomes of Straumann Standard Plus implants supported single crowns placed in non-augmented healed sites in the anterior maxilla: a 5-8 years retrospective study. Clin Oral Implants Res. 2016;27(1):106-112.

13. Boardman N, Darby I, Chen S. A retrospective evaluation of esthetic outcomes for single-tooth implants in the anterior maxilla. Clin Oral Implants Res. 2016;27(4):443-451.
14. Angkaew C, Serichetaphongse P, Krisdapong S, Dart MM, Pimkhaokham A. Oral health-related quality of life and esthetic outcome in single anterior maxillary implants. Clin Oral Implants Res. 2017;28(9):1089-1096.

15. Hurzeler MB, von Mohrenschildt S, Zuhr O. Stage-two implant surgery in the esthetic zone: a new technique. Int J Periodontics Restorative Dent. 2010;30(2):187-193.

16. Palacci P, Nowzari H. Soft tissue enhancement around dental implants. Periodontol 2000. 2008;47:113-132.

17. Gonzalez D, Cabello G, Olmos G, Ninoles CL. The saddle connective tissue graft: a periodontal plastic surgery technique to obtain soft tissue coronal gain on immediate implants - a case report. Int J Esthet Dent. 2015;10(3):444-455.

18. Fickl S, Zuhr O, Wachtel H, Bolz W, Huerzeler M. Tissue alterations after tooth extraction with and without surgical trauma: a volumetric study in the beagle dog. J Clin Periodontol. 2008;35(4):356-363.

19. Thoma DS, Buranawat B, Hammerle CH, Held U, Jung RE. Efficacy of soft tissue augmentation around dental implants and in partially edentulous areas: a systematic review. J Clin Periodontol. 2014;41(Suppl 15): S77-S91.

20. Schneider D, Grunder U, Ender A, Hämmerle CH, Jung RE. Volume gain and stability of peri-implant tissue following bone and soft tissue augmentation: 1-year results from a prospective cohort study. Clin Oral Implants Res. 2011;22(1):28-37.

21. Linkevicius T, Puisys A, Linkeviciene L, Peciuliene V, Schlee M. Crestal bone stability around implants with horizontally matching connection after soft tissue thickening: a prospective clinical trial. Clin Implant Dent Relat Res. 2015;17(3):497-508.

22. Thoma DS, Mühlemann S, Jung RE. Critical soft-tissue dimensions with dental implants and treatment concepts. Periodontol 2000 2014;66(1):106-118.

23. Strebel J, Ender A, Paque F, Krahenmann M, Attin T, Schmidlin PR. In vivo validation of a three-dimensional optical method to document volumetric soft tissue changes of the interdental papilla. J Periodontol. 2009;80(1):56-61.

24. Akcali A, Trullenque-Eriksson A, Sun C, Petrie A, Nibali L, Donos $\mathrm{N}$. What is the effect of soft tissue thickness on crestal bone loss around dental implants? A systematic review. Clin Oral Implants Res. 2017;28(9):1046-1053.
Clinical, Cosmetic and Investigational Dentistry

\section{Publish your work in this journal}

Clinical, Cosmetic and Investigational Dentistry is an international peer-reviewed, open access, online journal focusing on the latest clinical and experimental research in dentistry with specific emphasis on cosmetic interventions. Innovative developments in dental materials, techniques and devices that improve outcomes and patient satisfac-

\section{Dovepress}

tion and preference will be highlighted. The manuscript management system is completely online and includes a very quick and fair peerreview system, which is all easy to use. Visit http://www.dovepress com/testimonials.php to read real quotes from published authors. 